\title{
Participation of gastrointestinal microbiome in the pathogenesis and symptoms of autism according to the theory of brain-intestinal axis interaction
}

\author{
Aneta Marta Stanisławek', Maria Kozioł-Montewka' \\ ${ }^{1}$ Department of Health, Pope John Paul II State School of Higher Education in Biala Podlaska, Poland \\ Stanisławek A.M, Kozioł-Montewka M. Participation of gastrointestinal microbiome in the pathogenesis and symptoms of autism according \\ to the theory of brain-intestinal axis interaction. J Pre-Clin Clin Res. 2017; 11(2): 153-156. doi: 10.26444/jpccr/81300
}

\begin{abstract}
Autism is a disorder involving a number of symptoms. It is included in the overall development disorders. The disease is characterized by spreading and progressive behavioural disorders, usually manifesting in early childhood and continuing also through adulthood. Epidemiological data emphasize the importance of the problem and the need to develop studies using modern molecular methods and next-generation sequencing techniques. and in the 1990's - 10-20 per 10,000. Latest indexes show that child autism and Asperger syndrome affect 1 in 38 children. Recently, there has been published a detailed study on the intestinal microflora in children with autism, showing differences in the spectrum of microorganisms in sick and healthy children. One of the most striking discoveries is the fact that functions of the intestinal microflora and functions of the brain are connected. Therefore, it is possible that microbiome may influence a person's behaviour and mental health. In the past, the impact of intestinal microflora on the development of autism was ignored, but today it is important. Digestive tract disorders occurring in children with autism can have various natures and locations. As of now, a single autism-specific digestive tract pathology cannot be claimed to exist. As in elimination diets, treatment should be conducted on an individual basis.
\end{abstract}

\section{Key words}

autism, autism spectrum disorder, intestinal microbiota

\section{INTRODUCTION}

Autism is a disorder involving a number of symptoms. It is included in the overall development disorders characterized by the occurrence of four groups of characteristics: impairment of social functioning, communication disorders, a limited and recurring pattern of interests and activities, and early onset [1].

The disease involves the spreading and progression of behavioural disorders, usually manifesting in early childhood and continuing also through adulthood [2]. The brain of a child with autism works differently that of a child who is developing in a typical way. Consequently, the autistic child perceives the world differently and reacts differently. A special risk group are children those having close relatives with autism and premature babies with low birth weight. Disturbing signals appear before a child is three years old. The therapy must be tailored to the individual abilities and needs, because autism is a word that covers a whole spectrum of disorders. There are theories about the primary psychological deficit in autism. Although some children are diagnosed with chromosomal abnormalities or metabolic disorders, to-date, however, no one has been able to clarify the etiological factors of the disease. Symptoms of the so-called 'autistic regress' occur in about one-third of cases. Before the second year of life, thge child stops speaking and interacting with the environment $[1,2]$.

Adress for correspondence: Aneta Marta Stanisławek, Department of Health, Pope John Paul II State School of Higher Education in Biala Podlaska, Sidorska 95/97, 21-500 Biala Podlaska, POLAND

E-mail: a.stanislawek@andarbp.pl

Received: 18 September 2017; accepted: 19 December 2017
Etiology of autism. The etiology of autism has raised the interest of many researchers but is still relatively poorly understood $[3,4,5]$. It is now recognized that this disease is conditioned by many factors. Many studies support the fact that the cause of child autism is organic damage to the CNS. However, to-date, no one has managed to pinpoint brain structure damage that would be responsible for the symptoms of the disease. As shown by recent studies, changes in the CNS in autism are not located in a specific region of the brain, but include a variety of its structures [6].

It is presumed that genetic predisposition and environmental factors have impact on this disease manifesting itself [7]. Intestinal symptoms that often go hand-in-hand with autism, have not been given much thought until recently [8]. In 1998, the Lancet journal published an article describing eating disorders of abdominal pain, diarrhea, and flatulence in twelve patients with autism. These symptoms occurred in parallel with the intensification of autistic symptoms. Endoscopy revealed swollen lymph glands in the form of encysted bodies in the submucosa of the intestinal wall. There were also changes in mucosa, such as redness, loss of vascularity, and graininess. The same group of researchers later described similar symptoms in a larger number of patients (60), characterizing this pathology as a new variant of IBD (Inflammatory Bowel Disease) without typical symptoms characteristic of Crohn's disease or ulcerative enteritis [9].

Intestinal microbiota and Autism Spectrum Disorder. Recently, there have been publications about a detailed study of intestinal microflora in children with autism, showing 


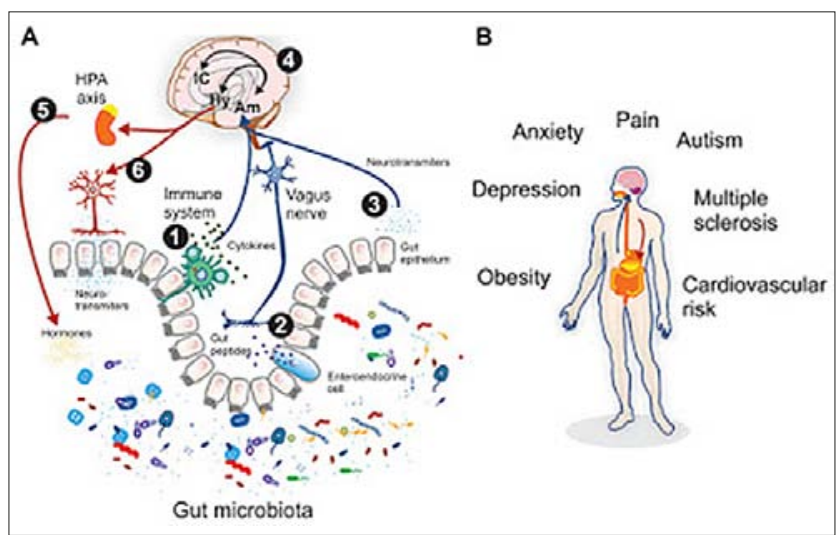

Figure 1. FIGURE 1. (A) Microbiota-gut-brain (MGB) axis. Direct and indirect pathways support the bidirectional interactions between the gut microbiota and the central nervous system (CNS); involving endocrine, immune and neural pathways. On the afferent arm (blue arrows): (1) lymphocytes may sense the gut lumen and internally release cytokines which can have endocrine or paracrine actions, (2) Sensory neuronal terminals, such as on the vagus nerve may be activated by gut peptides released by enteroendocrine cells, (3) Neurotransmitters or its precursors produced as microbiota metabolites may reach the gut epithelium having endocrine or paracrine effects. (4) Centrally, after brainstem relays (e.g., nucleus tractus solitarii) a discrete neural network has been described consistently involving the amygdala (Am) and the insular cortex (IC) as main integrators of visceral inputs. Consistently hypothalamic $(\mathrm{Hy})$ activation initiates the efferent arm (red arrows): (5) corticosteroids, release as results of the hypothalamic-pituitaryadrenal (HPA) axis activation, modulates gut microbiota composition. (6) Neurona efferent activation may include the so called "anti-inflamatory cholinergic reflex" and/or sympathetic activation, both liberating classical neurotransmitters that may affect directly the gut microbiota composition. (B) Health conditions affected by the MGB axis [45]

differences in the spectrum of microorganisms in sick and healthy children. Human intestine microflora is a complex ecosystem of microorganisms which play an important role in the health of the host. This very complex ecosystem has been underestimated. One of the most striking discoveries is the fact that functions of the intestinal microflora and functions of the brain are connected. Therefore, it is possible that microbiome may influence a person's behaviour and mental health.

The concept of a brain-gut axis, while taking into account the composition of the digestive tract microbiome, presents the possibility of communication between the central nervous system and the intestinal tract $[10,11]$ - information is exchanged in both directions. The intestinal flora may take part in the functions of the central nervous system by affecting the ability to synthesize neuroactive signaling molecules, such as acetylcholine catecholamine, gammaaminobutyric acid, histamine, melatonin, serotonin, or the production of substances that mimic their effects [12].

On the other hand, when it comes to this interaction, the composition of the intestinal microflora is influenced by emotional stress, along with other effects of intestinal physiology, such as changes in motor skills, an increase in the permeability of the intestine, among others [13]. Advances in molecular medicine in the field of sequencing, in particular introduction of the NGS (Next Generation Sequencing), allowed the identification of a vast number of microorganisms in the small intestine, which may significantly affect the function of the brain-gut axis [14]. Numerous studies show that the dysfunction of the braingut axis can lead to inflammation and functional changes of the digestive tract. Moreover, altered composition of the intestinal microflora in children affects maturation of the central nervous system, and in this way may facilitate the development of mental disorders, such as autism, depression or disorders leading to bulimia.

Causal relations between the psyche and the microbiome are examined both in terms of autism causes and development mechanisms, and also in order to find new therapeutic possibilities, such as following a proper diet, using probiotics and faecal bacterial transplantation $[10,11,15,16]$. The hypothesis about the relationship between autism and digestive tract microbiome considers the autism pathogenesis aspects, in particular, which microbiome changes have the strongest link with ASD (Autism Spectrum Disorders) symptoms, and which may be a side-effect of a treatment or a disease [15]. Neuropsychiatric changes, such as depression, bipolar disorders and autism, although the pathogenesis of these disorders varies in terms of microbiome, considers immunological effects, changes in intestinal permeability and penetration of bacterial products into the bloodstream, with possible penetration through the blood/brain barrier. Upsetting the microbiome composition may also have a secondary impact by affecting serotonin-producing cells, which affects the neurotransmitter synthesis stage [17].

With the relationship between the digestive tract's microbiome and autism through the gut-brain axis, the impact of diet on mutual interactions and the microbiome composition should be considered. Previous studies on the microbiome characteristics in children with autism are fragmentary and diverse. Studies by Song et al. showed a significant increase of Clostridium bolteae and Clostridium groups I and IX in the faeces of children with autism, compared to healthy children [18]. In turn, studies by Finegold et al., conducted on thirty-three children with varying degrees of autism symptoms, showed differences at cluster level between Bacteroides and Firmicutes, depending on the severity of symptoms, as well as the increase of Bacteroides vulgatus and Desulfovibrio spp, compared to healthy children [19]. Studies by Lv. Wang et al. found a significant amount of Sutterella spp and $R$. momenty in the faeces of children with autism and functional disorders of the digestive tract, compared to healthy children, previous studies were performed in intestinal biopsies [20]. In this regard, studies on the digestive tract's microflora in children with autism can be used as an additional way to search for diagnostic tests, therapeutic possibilities including diet and antibiotic therapy and preventive actions.

Various aspects of the relationship between the microbiome of the digestive tract and autism were analyzed in 2014 during the GM Workshop at Arkansas Children's Hospital Research Institute, as part of the First International Symposium on the Microbiome in Health and Disease 2014, where the working group included clinicians, researchers and parents of children with autism. Attempts were made to address three important issues: 1) whether there is a link between the ASD symptoms and changes in the digestive tract's microbiome; 2) whether manipulating the microbiome composition as a therapeutic action can be safe; and 3) whether a deeper understanding of the presumed mechanisms responsible for organic and behavioural changes in children with autism is possible.

In this regard, the critical element is the knowledge of microbiome formation in infants. Thanks to numerous studies, knowledge of the processes occurring has been significantly broadened. Until recently, it was thought that children are born sterile, and during growth, from the very first days, they are acquiring intestinal microflora from their 
environment [21]. However, the process of microorganism colonization may begin before birth as a result of transfer between mother and child, and during birth through the placenta [20], as well as due to changes in the mother's microbiome during pregnancy $[20,22,23]$. Vaginal birth allows the direct transfer of bacteria from the birth canal and anal area into the child $[24,25,26]$. Early microflora colonization in the intestines of infants is also promoted by breastfeeding $[27,28,29]$. Bacterial colonization of the intestines, which starts during the prenatal period, may modulate the development of the host's nervous system. This occurs via signaling pathways, such as the vagus nerve - a direct connection between the intestines and the central nervous system.

Starting from infancy and early childhood, the intestinal ecosystem undergoes changes that are related to microbiological inheritance, with factors such as diet and the immune system shaping the intestine microbiome composition. The process of building the intestine microflora is still poorly understood, but it is believed that the time it takes to colonize the intestine microflora of crucial importance is $[27,30,45]$. Intestinal microbiome can be maintained for many years or even a lifetime with little changes in its composition [31, 32, 33, 34, 35, 36]. Human intestinal microflora is dominated by anaerobic bacteria (such as Clostridium spp.). It is also known that some bacilli can produce toxins (enterotoxins and neurotoxins). In 1998, Ellen Bolte, the mother of an autistic child, was the first to propose the hypothesis about the role of bacteria in autism development [37]. This hypothesis was based on observing the parents of autistic children who, before the disease, had used broad-spectrum antibiotics, mostly due to chronic middle ear inflammation. The use of antibiotics was usually followed by diarrhea, then the child stopedp talking, lost contact with the environment, and developef further symptoms of autism. Based on the above observation, a group of American researchers [38], concluded that frequent use of antibiotics in these children causes disturbances of intestinal microflora, or 'colonization resistance factor' [2], which leads to proliferation of neurotoxin-producing pathogenic bacterial species (one or several) in the digestive tract. The initial goal of the study was to find microorganisms that produce neurotoxins which affect the central nervous system via the vagus merve which is responsible for the innervation of the small intestine; hence the idea to look for possible factors responsible for the autism symptoms also in the upper parts of the digestive tract where, in addition to Clostridium bacteria, species of Gram-negative bacteria hah been detected, unusual in healthy children, for example, Cetobacterium somerae sp. nov [9]. Neurotoxins may be responsible for at least some of the clinical symptoms of autism, therefore appropriately selected antibiotics administered to a patient with autism should at least alleviate the disease symptoms.

The next hypothesis about the possible toxic effects of metabolic products (both typical and atypical) of bacteria that live in the intestines was established on the basis of the peculiar odour of the faeces of children with autism, resembling the smell of moth balls, which was observed by parents. This smell may be caused by indole or skatole (3-methyl-indole) produced by microorganisms out of tryptophan. However, the presence of other factors, such as naphthalene or its derivatives, may also promote the production of this characteristic odour. There are also other hypotheses, including those indicating the role of auto-antibodies in autism. In autism pathogenesis, many publications set auto-antibodies against axon filament proteins, glial fibrillary acidic protein or myelin basic protein [2].

\section{CONCLUSIONS}

In the past, the impact of intestinal microflora on the development of autism was ignored, but it is important in the context of yeast and clostridium. Treatment of the hypertrophy resulted in substantial clinical improvement in some cases. Autistic people are known to have increased tartaric acid and arabinose. Arabinose is involved in protein binding disorders and may therefore affect neuronal connections, causing the autism symptoms. Tartaric acid from yeast may have a direct toxic effect on muscles, and it is a critical Krebs cycle transmitter, providing material for gluconeogenesis. While it is obvious that the above-mentioned bacterial flora metabolites may cause autism symptoms, other aspects are also important. The causes may exist altogether but vary from individual to individual, hence different symptoms. Digestive tract disorders occurring in children with autism can have various natures and location. At the moment, it is not possible to determine the existence of one pathology of the digestive system characteristic for autism. As in elimination diets, treatment should be conducted on an individual basis [39].

Despite a number of studies conducted on the autism etiopathogenesis and treatment, the problem has not yet been fully investigated and explained. The results of the studies indicate that the intestinal microflora in autistic children is different from that of healthy children, both qualitatively and quantitatively; therefore, further comparative research of intestinal microbiome of autistic and healthy children is well-founded. It is intended to clarify the details of these differences, for instance, in terms of toxigenicity, clonal propagation and the possible impact on ASD symptoms, therapy and medication. Further studies on intestinal flora and full identification of species will allow for more effective treatment that will not lead to a complete recovery, but will significantly improve the condition of the patient [39].

Epidemiological data emphasize the importance of the problem and the need to develop studies using modern molecular methods and next-generation sequencing techniques. The first epidemiological studies on autism, conducted in the 1960s, stated a ratio of $4-6$ per 10,000 , this increased in the 1990's to $10-20$ per 10,000 [40, 41, 42]. Latest indices show that child autism and Asperger syndrome affect 1 in 38 children. This is much more often than previously thought. It occurs four times more often in boys than in girls $[43,44]$. Also, more than two-thirds of autism cases are not diagnosed or treated according to the American-Korean-Canadian research. What is most disturbing, however, is that more than two-thirds of ASD cases in school children have not been diagnosed or treated. The Synapsis Foundation, which has been helping people with autism and their families for twenty-five years, estimated that out of approximately 400,000 children born in Poland in 2015 , approximately 15,000 will be at risk of having this disorder, while approx. 1,500 will definitely receive such a diagnosis. Scientists blame non-uniform diagnostic criteria and lack of complete epidemiological studies. 


\section{REFERENCES}

1.Chrościńska-Krawczyk M, Jasiński M. Autyzm dziecięcy- współczesne spojrzenie. Neurol Dziec. 2010; 19: 38: 75-78.

2. Martirosian G. Beztlenowa mikroflora jelitowa a patogeneza autyzmu? Postepy Hig Med Dosw. 2004; 58: 349-351.

3. Popielarska A, Popielarska M. Psychiatria wieku rozwojowego. Warszawa: PZWL; 2000; 67-102.

4. Goodman R, Scott S. Psychiatria dzieci i młodzieży. Wrocław. Urban \&Partner. 2000.

5. Wolańczyk T, Komender J. () Zaburzenia emocjonalne i behawioralne u dzieci. Warszawa PZWL. 2005.

6. Paya Gonzalez B, Fuentes Menchaca N, et al. Neurobiology of autism: neuropathology and neuroimaging studies. Actas Esp. Psiquiatr. 2007; 35: 271-276.

7. Yates K, Le Couteur A. Diagnosing autism. Paediatrics and Child Health 2009; 19: 55-59.

8. Wakefield AJ, Antony A, Murch SH, et al. Enterocolitis in children with developmental disirders. Am J Gastroenterol. Sep 2000; 95(9): 2285-9ok5.

9. Martirosian G. Spory bakterii Clostridium spp. w patpmechanizmie autyzmu.Wiadomości lekarskie 2009; LXII: 2: 119-122.

10. Konturek PC, Zopf Y. Gut microbiome and psyche: paradigm shift in the concept of brain-gut axis. MMW Fortschr Med. 158 Suppl 2016. 4: 12-6

11. Ochoa-Repáraz J, Kasper LH. The Second Brain: Is the Gut Microbiota a Link Between Obesity and Central Nervous System Disorders? Curr Obes Rep. 2016; 1: 51-64.

12. Petra AI, PanagiotidouS, HatziagelakiE, StewartJM, Conti P, Theoharides TC. Gut-microbiota-brain axis and effect on neuropsychiatric disorders with suspected immune dysregulation. Clin Ther. May 1; 2015; 37(5): 984-995.

13. Konturek PC, Brzozowski T, Konturek SJ. Stress and the gut: pathophysiology, clinical consequences, diagnostic approach and treatment options. J Physiol Pharmacol. 2011; 62: 591-9.

14. Weiner M., Kubajka M. Tularemia - serious zoonotic disease. Health Problems of Civilization 2015; 1(9): 39-46.

15. McDonald D, Hornig M, Lozupone C, Debelius J, Gilbert JA, Knight R. Towards large-cohort comparative studies to define the factors influencing the gut microbial community structure of ASD patients. Microb Ecol Health Dis. 2015; 26: 26555.

16. Toh MC, Allen-Vercoe E. The human gut microbiota with reference to autism spectrum disorder: considering the whole as more than a sum of its parts. Microb Ecol Health Dis. 2015; 26: 26309.

17. Desbonnet L, Garrett L, Clarke G, Bienenstock J, Dinan TG. The probiotic Bifidobacteria infantis: An assessment of potential antidepressant properties in the rat. J Psychiatr Res. 2008; 43: 164-74.

18. Song Y, Liu C, Finegold SM. Real-time PCR quantitation of clostridia in feces of autistic children. Appl Environ Microbiol. 2004; 70: 6459-65.

19. Finegold SM, Dowd SE, Gontcharova V, Liu C, Henley KE, Wolcott RD Youn E, Summanen PH, Granpeesheh D, Dixon D, Liu M, Molitoris DR, Green JA. Pyrosequencing study of fecal microflora of autistic and control children. Anaerobe 2010; 16: 444-53.

20. Wang L, Christophersen CT, Sorich MJ, Gerber JP, Angley MT, Conlon MA. Increased abundance of Sutterella spp. and Ruminococcus torques in feces of children with autism spectrum disorder. Mol Autism. 2013; 4: 42-46.

21. Mackie RI, Sghir A, Gaskins HR. Developmental microbial ecology of the neonatal gastrointestinal tract. Am J Clin Nutr. 1999; 69: 1035S-45S

22. Koren O, Goodrich JK, Cullender TC, Spor A, Laitinen K, Backhed HK, et al. Host remodeling of the gut microbiome and metabolic changes during pregnancy. Cell. 2012; 150: 470-80.

23. Aagaard K, Riehle K, Ma J, Segata N, Mistretta TA, Coarfa C, et al. A metagenomic approach to characterization of the vaginal microbiome signature in pregnancy. PLoS One. 2012; 7(6): e36466.
24. Schultz M, Gottl C, Young RJ, Iwen P, Vanderhoof JA. () Administration of oral probiotic bacteria to pregnant women causes temporary infantile colonization. J Pediatr Gastroenterol Nutr. 2004; 38: 293-7.

25. Makino H, Kushiro A, Ishikawa E, Muylaert D, Kubota H, Sakai T, et al. Transmission of intestinal Bifidobacterium longum subsp. longum strains from mother to infant, determined by multilocus sequencing typing and amplified fragment length polymorphism. Appl Environ Microbiol. 2011; 77: 6788-93.

26. Dominguez-Bello MG, Costello EK, Contreras M, Magris M, Hidalgo $\mathrm{G}$, Fierer N, et al. Delivery mode shapes the acquisition and structure of the initial microbiota across multiple body habitats in newborns. Proc Natl Acad Sci USA. 2010; 107: 11971-5.

27. Penders J, Thijs C, Vink C, Stelma FF, Snijders B, Kummeling I, et al. Factors influencing the composition of the intestinal microbiota in early infancy. Pediatrics 2006; 118: 511-21.

28. Gura T. Nature's first functional food. Science 2014; 345: 747-9.

29. De Leoz ML, Kalanetra KM, Bokulich NA, Strum JS, Underwood MA, German JB, et al.J Proteome Res. Human milk glycomics and gut microbial genomics in infant feces shows correlation between human milk oligosaccharides and gut microbiota: a proof-of-concept study. 2014. [Epub ahead of print].

30. Voreades N, Kozil A, Weir TL. Diet and the development of the human intestinal microbiome. Front Microbiol. 2014; 5: 49.

31.Schloss PD, Iverson KD, Petrosino JF, Schloss SJ. The dynamics of a family's gut microbiota reveal variations on a theme. Microbiome. 2014; $2: 25$.

32. Koenig JE, Spor A, Scalfone N, Fricker AD, Stombaugh J, Knight R, et al. Succession of microbial consortia in the developing infant gut microbiome. Proc Natl Acad Sci USA. 2011; 108: 4578-85.

33. Costello EK, Lauber CL, Hamady M, Fierer N, Gordon JI, Knight R. Bacterial community variation in human body habitats across space and time. Science 2009; 326: 1694-7.

34. David LA, Materna AC, Friedman J, Campos-Baptista MI, Blackburn MC, Perrotta A, et al. Host lifestyle affects human microbiota on daily timescales. Genome Biol. 2014; 15: R89.

35. Jalanka-Tuovinen J, Salonen A, Nikkila J, Immonen O, Kekkonen $\mathrm{R}$, Lahti L, et al. Intestinal microbiota in healthy adults: temporal analysis reveals individual and common core and relation to intestinal symptoms. PLoS One. 2011; 6 e23035.

36. Martinez I, Muller CE, Walter J. Long-term temporal analysis of the human fecal microbiota revealed a stable core of dominant bacterial species. PLoS One. 2013; 8 e69621.

37. Bolte ER. Autism and Clostridium tetani. Med Hypotheses. Aug 1998; 51(2): $133-44$.

38. Sandler RH, Finegold SM, Bolce ER, et al. Short-term benefis from oral vancomycin treatment of regressive-onset autism. J Child Neurol Jul. 2000; 15(7): 429-35.

39. Bingham M. Autyzm i flora jelitowa. Food Microbial Sciences Unit, Science and Technology Centre, Earley Gate, Uniwersity of Reading, Whiteknights Road, Reading, Berkshire, 2011; UK. RG6 6BZ.

40. Michałowicz R, Jóźwiak S. Neurologia dziecięca. Wrocław. Urban \&Partner 2000.

41. Pisula E. Małe dziecko z autyzmem. Gdańsk: Gdańskie Wydawnictwo Psychologiczne 2005.

42. Bryson SE. Brief report: Epidemiology of autism. Journal of autism and Developmental Disorders 1996; 26(2): 165-167.

43. Baird G, Simonoff E, Pickles A, et al. Prevalences of disorders of the autism spectrum in the population cohort of children in south Thames: the specjal Needs and autism Project (SNAP). Lancet. Jul 2006; 15: 368(9531): 210-5.

44. Plauche Johnson C, Myers SM. Council on Children with Disabilities: Identification and evaluation of children with autism spectrum disorders. Pediatrics 2007; 120: 1183-1215.

45. Montiel-Castro AJ, Gonzalez-Cervantes RM, Bravo-Ruiseco G, Pacheco-Lopez G. The microbiota-gut-brain axis: neurobehavioral correlates, health and sociality. Front. Integr. Neurosci. 07 October 2013; 7: 70: 1-16. 